\title{
Professionalisation in Adventure Management: Competence Profile of Outdoor Instructors
}

\author{
Sandra Mueller ${ }^{1}$, Manuel Sand ${ }^{2, *}$ \\ ${ }^{1}$ University of Applied Management, Germany \\ ${ }^{2}$ Institute for Outdoor and Adventure, University of Applied Management, Germany
}

Copyright $\bigcirc 2017$ by authors, all rights reserved. Authors agree that this article remains permanently open access under the terms of the Creative Commons Attribution License 4.0 International License

\begin{abstract}
Outdoor instructors require a set of competences enabling them to meet the demands of different training groups. Yet, it is not evident what competences are of particular significance and what roles the aspects communication and leadership play. Current research is often based on the subjective experiences of the corresponding researchers. Only very few contributions are based on empirical data such as [1-3]. Some researches specifically address the aspects leadership and communication [4-7], yet up to now a competence profile has not been developed. A systematic data-based analysis regarding a comprehensive competence model for outdoor instructors is lacking. This qualitative pilot study seeks to gain insights regarding important competencies of outdoor instructors with a focus on leadership and communication. Ten selected outdoor instructors were interviewed using qualitative methods. Results show that personal skills are more important than specialist knowledge. Trainers should be authentic, interacting with groups and aware of customer needs. Communication skills are important, as well as humour and sympathy and understanding in terms of communication. With a focus on leadership optimism, decision-making ability and judgement are essential skills. No consistent competence pattern could be determined, but a set of valuable research questions for future studies could be defined.
\end{abstract}

Keywords Outdoor Training, Competences, Communication, Leadership

\section{Introduction}

An outdoor instructor is an instructor (outdoor educator) who conducts predominantly sporting activities with groups and in doing so pursues educational goals; in addition, he should master the respective medium and have a pedagogical education [8]. Outdoor trainings try to provide learning outcomes in order to achieve behavioural change [9]. Therefore it is essential for outdoor instructors to design specific tasks for the participants and to reflect on the group behaviour while solving the task afterwards [8]. Several different terms and definitions of an outdoor instructor exist, especially with an international perspective [10]. In German the term Erlebnispädagoge is universally used for trainers that work with under-aged groups' outdoors [9]. It sometimes can be applied to both for educators and instructors [11]. In this paper an outdoor instructor is considered to be a person working with adults in an outdoor setting to enable them to learn and develop their personalities by overcoming challenging situations. A standardised education of outdoor instructors currently does not exist in Germany. Therefore a wide range of different concepts and standards are available. The literature gives no clear classification of exactly which skills an outdoor instructor needs to possess in order to perform his trade. Koenig and Koenig [8, p. 72] emphasize this lack of classification for the German market: "As different as training programmes for instructors are, as different is the discussion about what makes a good Outdoor Trainer and which qualification he needs" (translated from German by the authors). This study focuses on male outdoor trainers only, as they are predominant on the German outdoor training market. Research investigating the female outdoor trainer is planned for the next future. The authors expect a general difference in the data between the sexes.

The question about requisite skills of instructors for their trade leads to the term competence. Competences are becoming increasingly important in commercial, pedagogical and psychological settings. It has become a key term in political, economic and educational realities $[12,13]$. This current study also examines communication and leadership as important aspects that are essential for good outdoor instructors, according to literature and current research $[5-7,14]$.

\subsection{Competence}

Identifying, understanding, judging and developing 
competencies are decisive challenges to ensure compatibility on the market and in life. The German educational system has changed from teaching knowledge to teaching competencies $[12,15,16]$. This trend can also be found in trainings on the job: "The trade rivalry of the future will be fought as a competence rivalry" $[15, \mathrm{p} .21]$. The term competence has been discussed in detail by Apitzsch [12] and Beck [17], and based on their research a summary of the different views on competences can be offered as follows: Competences can be interpreted as knowledge-based cognitive competences, as ability-based functional competence, as motivational and emotional-based psychological competences or as a permitting judicial-organizational competence.

Given the special importance in this study on both leadership competence and communication competence, a few general thoughts need to be considered regarding both competences in the context of outdoor trainings: Rohwedder [18] acknowledges that leadership and communication are closely connected; however, he also emphasizes the importance of differentiating between personal competences and social competences.

As mentioned above, there are to date no specific competence models of outdoor instructors. Given that the competency rivalry has already started, a framework for outdoor instructors becomes increasingly relevant, as the industry in Germany is currently searching for clear guidelines defining what an outdoor instructor should be able to do (and which qualifications are necessary).

Therefore, this study examines competences that are currently being taught to outdoor instructors. According to the guidelines for teaching outdoor instructors of the German Association of Individual and Outdoor Education (GAIOE) [19], competences are defined as: "general behavioural dispositions - or potentials - in terms of abilities, skills, strategies and, as the case may be, attitudes" ( p. 4; translated from German by the authors).

Far more research has been conducted regarding competences of coaches in team sports [12]. This direction of research provides a relevant basis for this current study as it contributes to the theoretical framework, given the parallel parameters identified in the literature. Team sports and outdoor groups work on the basis of a cooperative team, which is instructed by a trainer / outdoor instructors, using an individual approach with results that are relevant for the team and trainer as outdoor instructors are enabling this process [11, 12]. Nevertheless the team/group is responsible for their progress. Trainer and instructor reflect individual and collective behaviour and help to improve performance $[8,20]$.

Therefore studies of the field of team sports are considered as fundamental input for the research in this study, as well as work on leadership competences by Heyse and Erpenbeck [15], Koenig [21] and on communicational competences by Muckenhaupt, Grehl and Lange [22]. Understanding the process of leading a team outdoors and communicating with them as a managerial competence, the competence concept by Heyse and Erpenbeck [15] offers an appropriate basis for this study. The model has established itself in German competences research, as it identifies essential competences for specific jobs and fields [23]. It has been successfully used in numerous studies [22, $24,25]$. Its relevance for this current study is increased by the fact that it has been used in a team sport study [12].

The concept of competence defined by Heyse and Erpenbeck [15] provides a basic framework for this current study: "Competences are founded on knowledge in a narrower sense and constituted on rules, values and norms, personalised by exteriorisation processes, allotted as skills, consolidated by experience and put into practice by one's will" $[15$, p. XI].

\subsection{Leadership}

In Germany and other German-speaking regions in Europe, a well-known and accepted definition of leadership (Führung) is provided by Rosenstil [16, p. 71], and will be applied within the context of this current study: "Leadership is the deliberate exercise of influence on people."

It has been widely discussed whether successful leadership depends on personality traits or applied leadership skills. Evidence could only be found for specific situations, and generalizations to other population are not acceptable according to Rosenstiel. Therefore, it is important to analyse the leadership setting [16]. Avolio and Bass [26] offer the transformational leadership scheme which promotes the development of the follower by attractive tasks, positive support and inspiration. The observable behaviour of the executive is at the centre of attention. This model is suitable for consideration within this current study since participants will gain personal development during outdoor trainings.

Leadership competences have also been examined for regular sport instructors. Koenig [21] reviewed leadership principles of team sports. He discovered that some coaches were more often successful than others. Lames [20] described success as an enumerable result consisting of goals and points. While this is a very simplistic and goal-oriented explanation and several parameters influence the success, it is still how sports coaches are rated today. Measuring success of outdoor instructors is far more difficult, as results depend on reaching goals that differ from training to training and from customer to customer. The aim of the outdoor instructor is to reach specific goals for the respective training group and subsequently a long-term establishment of results by reflecting the results and transferring them into everyday life [27]. The competences of the outdoor instructor are significant for a successful training because the experience of the instructor is, according to Buckley [14], essential for the result of the training. 
The definitions above show that success of outdoor trainings can be assessed from different points of view (outdoor instructor, contractor, training participant). It also becomes apparent, on the basis of the sources, that the instructor has a crucial effect on the success. His role is therefore the central point of the epistemological interest in this research.

Leading as part of management involves competences from all four competence groups by Heyse and Erpenbeck [15]. They describe leadership as a cross-sectional competence that defines itself in different context [15]. Aspects of leadership competences consist of different competences such as judgmental skills, organisational skills, credibility, personnel development, communicational skills, conflict resolution skills, decision-making skills, goal-orientated acting and leading.

Koenig [21] conducted research on leadership principles and leadership strategies responsible for success in team sports. He found five tasks that involve correlating leadership skills: Organisation, season planning, coping with troubles during the season, teambuilding as well as planning and controlling the training process. These tasks can be transferred to outdoor trainings when looking at a single training rather than at a whole season. Organising, planning, coping with troubles, teambuilding are said to be essential skills of outdoor trainers [8].

\subsection{Communication}

The study of communication over the years has resulted in many models and definitions that are used in a wide range of contexts across disciplines. Some of the most accepted or "classic" models include the Lasswell formula [28]: "Who says what, in what channel, to whom and with what effect" offers an operationalisation of communication on the basis of sender-receiver models such as by Shannon and Weaver [29]. Other communication models such as by Buehler [30], Chomsky [31], Wazlawik [32], or Schulz von Thun [33] can also be called essential for the term "communication" which covers a broad range. In conclusion, these models have been developed for media-based mass communication or for interpersonal conversation analysis. These models although respected and well-established in their disciplines are not yet validated for application. For communication within the field of outdoor sport, a clearly defined term has not yet been developed [14]. Consequently, given the lack of a sport-specific definition of communication, this pilot study relies upon classic definitions of communication.

\section{State of Research}

According to Koenig \& Koenig [8, p. 72] there is no standard profile of qualification currently available for outdoor instructors:
"As much as the trainings differ, as different is the discourse about what makes a good top grade outdoor instructor and what qualifications he should have" (p. 72 translated from German by the authors) [8].

Regarding the competences of leadership and communication there are some contributions, but provide only general answers: Rohwedder [18] subdivides into personal competences and social competences. Leadership and communication are, in his view, closely connected [18]. The professional organisation for individual and outdoor education attempts to provide a framework pertaining to the competence of trainers [19]: (a) it makes sense to distinguish between self-competence, social competence and professional competence (including methodological competence and professional expertise); (b) personality is the most significant criteria; (c) additional characteristics should be considered, such as "authenticity and empathy, openness to dialogue and flexibility, resilience and self-reflection" (p. 5; translated from German by the authors).

On an international level there is more literature on the topic of competences and outdoor instructors [2, 7, 34-36]. Some authors simply offer advice drawing on their knowledge from personal experiences and do not approach the topic scientifically $[4,6]$. Buell [34] was the first to investigate important competences for outdoor leadership. He found 230 different essential competences, although many of them can be classified as knowledge or experience (e.g. first-aid-skills, making fire) and not as competences, as defined in this current research study. Johnson and Johnson [35] came up with several different important skills, but could not narrow down the essential competences. The same accounts for work by Sugerman [3], who mentions a variety of different skills, and Ringer [1] who identifies important skills in relation to leadership. Phipps \& Swiderski [36] demonstrate the importance of soft skills, but state that they are difficult to measure. This is also mentioned by Shooter, Sibthorp and Paisley [2] when they state that there is no unified categorisation and definition of competences. They classify competences into two categories: soft-skills (interpersonal skills) and hard-skills (technical skills). They are also aware of the importance of experience and decision-making, but unlike previous classifications they agree that it should be considered separately [2]. A good outdoor instructor has a depth and breadth of experience to fall back on in difficult and unforeseen situations. He also has trained his decision-making skills and relies on his instincts or gut feeling to come up with the right decision. While this is important, it cannot be classified as a competence. Reference [2] developed a useful classification of competences, but did not isolate important competences.

Priest and Gass [7] in their review of the literature on competences of outdoor instructors identify 12 important competences: Technical skills, safety skills, environmental skills, organisational skills, instructional skills, facilitation 
skills, professional ethics, flexible leadership style, experience-based judgment, problem-solving skills, decision-making skills, effective communication.

As mentioned previously, when defining competences, some of the skills cannot be considered as competences. For example, technical skills and environmental skills are important skills of an outdoor instructor, but there are several competences that contribute to being good at those skills. It can be agreed that all aspects are of importance to outdoor instructors, but the specific competences that are important for those skills need to be discovered.

Heyse and Erpenbeck [15] define 64 important competences that can be arranged in four categories: professional expertise and methodological expertise, personal competence, socio-communicative competence and activity competence and decision-making competence (translated from German by the authors).

These competences have been tested and validated in professional settings and have also been used for sport trainers [12]. Therefore the Heyse and Erpenbeck competence model will be used in this study.

Knowing important competences is critical not only for selecting suitable instructors, but also to train them effectively. Such training and development will improve outdoor trainings, as competences are important for successful outcomes [14].

This study aims to identify important competences of outdoor instructors with a focus on leadership and communication. It makes use of the 64 competences of the competence atlas by Heisse and Erpenbeck [15] ensuring that specific competences are mentioned and results can be narrowed down more easily.

\section{Methods}

To deduce essential competencies of outdoor instructors with a focus on communication and leadership a qualitative study was implemented.

\subsection{Qualitative Approach}

The purpose of the pilot study was to collect data as the basis for an outdoor instructor qualifications profile and to generate topics and questions for further investigation and analysis. Through the qualitative data analysis of interviews, the intent was to obtain a large sample of relevant participants and by using open questions delve into deeper issues and nuances than accessible by standard questionnaires or surveys.

\subsection{The Sample}

The aim was to interview ten outdoor instructors within Bavaria in Germany. The authors opted for an interview group of ten outdoor instructors for the pre-study, since this size promised to be big enough to interview trainers from different backgrounds and to collect different views and opinions. It was important to compile a data set that not only reflected the specific everyday situation in this line of business (age, training, job profile), but also one that guaranteed the desired results expected regarding the required demands on the research questions (experience in leadership, professional experience and judgement experience).

To select experts for the study the following criteria were used for the selection and compilation of the sample. Experts included in the study were involved in at least one of the following tasks within their job. Seven had a management position with an outdoor training providers, five regularly held trainings and educational courses for instructors of outdoor trainings and seven regularly conducted outdoor trainings themselves. All ten interviewees were responsible for the selection of outdoor trainers within their jobs. Holding management positions as outdoor trainers gives insights into aspects of leadership and communication from both perspectives. Therefore these candidates were considered experts for both specific research topics.

In total, the interviewed persons have work experience ranging from 7 to 30 years $($ mean $=17.9$ years; median $=$ 15.5 years; $\mathrm{SD}=9.2$ ). This helps to ensure the comparability of the data related to a minimum requirement for professionalism. Outdoor instructors of different age groups can be successful. This is due to the vast range of trainings, training focus and training groups. The ages of our interview group are between 28 and 64 years (mean = 50.4 years; median $=47$ years; $\mathrm{SD}=11.7$ ). In regards to gender, the outdoor sport business is male-driven; this study focuses on male outdoor instructors, further interviews with female outdoor instructors will take place in the next step to compare results and understand to which extend gender is influential.

As mentioned above, no clear profile of qualification exists to date in Germany for this occupational group. Therefore the educational background is an important aspect. Six participants undertook an academic qualification, mostly with a degree in sport and/or pedagogy, three of the participants underwent training in adventure-based learning programmes and one has no formal subject-specific training, but plenty of experience.

\subsection{Data Collection and Evaluation}

The data were collected by means of a qualitative guideline for interviews according to Glaeser and Laudel [37] with a total of five questions for the application of the sample. Three questions were open questions asking about essential competencies in general, competencies essential for a successful training and competencies that are considered as personal strength's. Two questions were answered by the participants by means of competence cards based on the competence atlas by Heyse and Erpenbeck [15]. 
Participants were asked to choose the five most important cards on communication and leadership out of 64 competence cards. Since outdoor instructors work with specific methods and specifically targeted experiences in their trainings [9] this procedure was appropriate and effective in conveying the topic of the survey as clearly as necessary to the interviewed partners.

The procedure during the interviews was standardised and recorded by the authors increasing the reliability, validity and intended comparability of the questioning situation. The participants were asked two open questions about important competencies in general and competencies that are important for successful trainings. If something was missing or unclear the interviewer asked further questions. This was followed by the two questions about communication and leadership. The interviewees were asked to select the 5 most important competencies for the two aspects. The participants were then asked to explain what the competency means to them and why they selected it. This was important to analyse whether the definitions of the competencies matched the definitions in the literature. The interview ended with an open question about the participants personal strengths. The interviews lasted for 35 to 55 minutes.

The evaluation of the data from the transcribed interviews was carried out by qualitative content analysis according to Mayring [38]. The text was scanned for key information. Then the deduced information was separated into categories. After reviewing the data the categories found by the author's matched those of Heyse \& Erpenbeck. Therefore the four categories from the competence atlas by Heyse \& Erpenbeck were used: professional and methodological expertise, personal competence, socio-communicative competence, and activity competence and decision-making competence (see fig. 2). The application of the categories as well as the consistency of the definitions of term were critically examined several times during the evaluation process and confirmed during the course of action.

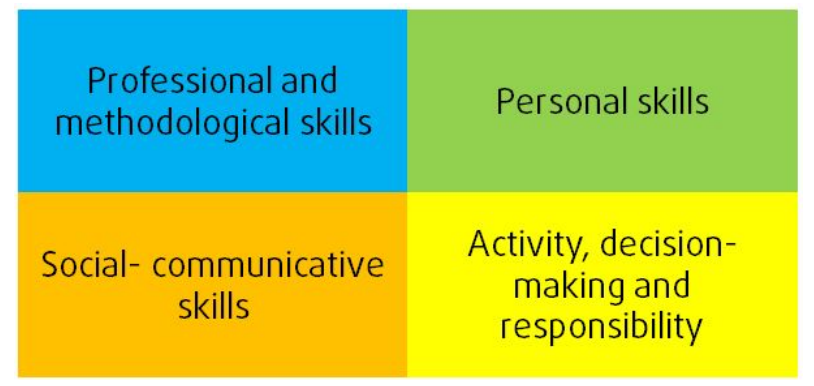

Figure 1. Categories for data evaluation

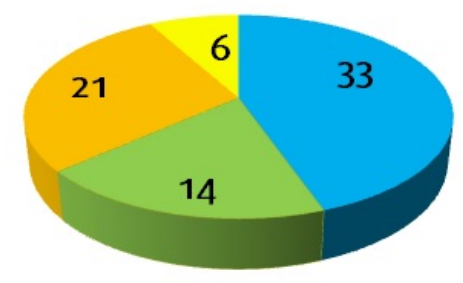

\section{- Professional- and methodological skills \\ Personal skills \\ Social- communicative skills \\ Activity, decision-making and responsibility}

Figure 2. Results Competences - Outdoor Instructor

\section{Research Results}

Within the qualitative research methods paradigm, the authors present the results of the content analysis including statements about frequency. This is an acceptable approach, supporting the interpretation of results, especially given differences in the statements by respondents. The results for the open questions and the questions using competence cards will be given separately.

\subsection{Open Questions}

The answers from the participants were very different and therefore it is difficult to develop certain themes. Interestingly the aspects of communication and leadership were not directly mentioned in the open questions, yet they are considered important in the questions about these two aspects. This leads to the conclusion that the interviewees find it difficult to identify important competences. Professional knowledge is important to all participants, yet they consider personal competences as more essential. "Important are the skills he has apart from the professional and methodological skills" (Participant 3).

Another emerging theme is required authenticity. It is essential that an outdoor instructor is credible and that he knows exactly what he talks about. As Participant 2 said: "being authentic: what I say is also what I think".

A good instructor can interact with groups and know what the customers are looking for. "He needs to want to interact with people and have some experience in life" (Participant 7). Other important competences describe a positive interaction with the customers ("He needs to be able to work with groups, have a good standing, has to be able to link up with people"; Participant 5), decision making skills and organisational skills. Participant 7 emphasises this by saying: "adapt to the current situation and react confident. 
In the end, it is essential to help the group to learn something and to take the outcomes home with them to positively change their behaviour. Participant 2 puts it this way: "He needs to be able to put himself in the situation of the participant, has to be able to reflect the outcomes and to start a process of transferring these into daily life". The interviewed outdoor instructors find it hard to eliminate important skills for this goal. Interestingly the interviewees own strength do not match the competences considered important in general and for a successful training.

The three open questions will now be analysed separately with a focus on how often competences of the four categories were mentioned.

Interview question one: What competences does an outdoor instructor have to possess?

For this question interview participants emphasized professional and methodological expertise in their answers: Professional knowledge is often regarded as an entry competence and is presupposed. Furthermore it was important to participants that the instructor is a mature personality. The interview participants identified the requirement of being able to interact with teams and that work should be focused on the needs of the customer. The interviews show that specialist knowledge is an important basis, but is not seen as an essential competence. Communication and leadership are not directly mentioned.

Interview question two: What competences of an instructor are important so that a training unit is verifiably successful?

According to the interviewees, instructor judgment and project organisation are significant. Also the instructor's personality is essential for the implementation. The interview participants focused mainly on successful communication. In general, the answers were very divergent, as each participant answered in regard to his own strengths.

\subsection{Competence Cards}

When using the card technique for the competence of communication, the following cards were preferred by the interviewees: communication skills; humour; credibility; sympathy and understanding.

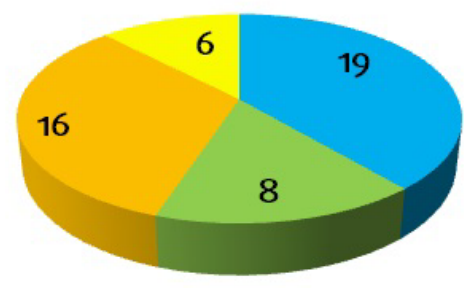

\section{- Professional- and methodological skills \\ - Personal skills \\ - Social- communicative skills \\ Activity, decision-making and responsibility}

Figure 3. Results "Important competences for successful training"

Interview question five: Which of the identified competences do you see as your strengths?

The interview participants often mentioned professional knowledge and analytical skills as their own strengths. Their own experience was also mentioned frequently.

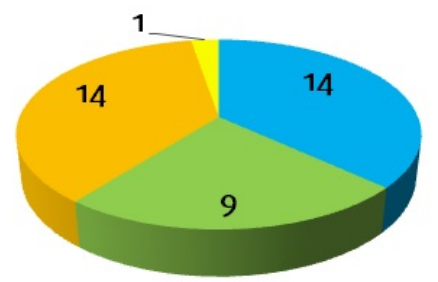

\section{- Professional- and methodological skills - Personal skills \\ - Social- communicative skills Activity, decision-making and responsibility}

Figure 4. Results "Own Strengths"

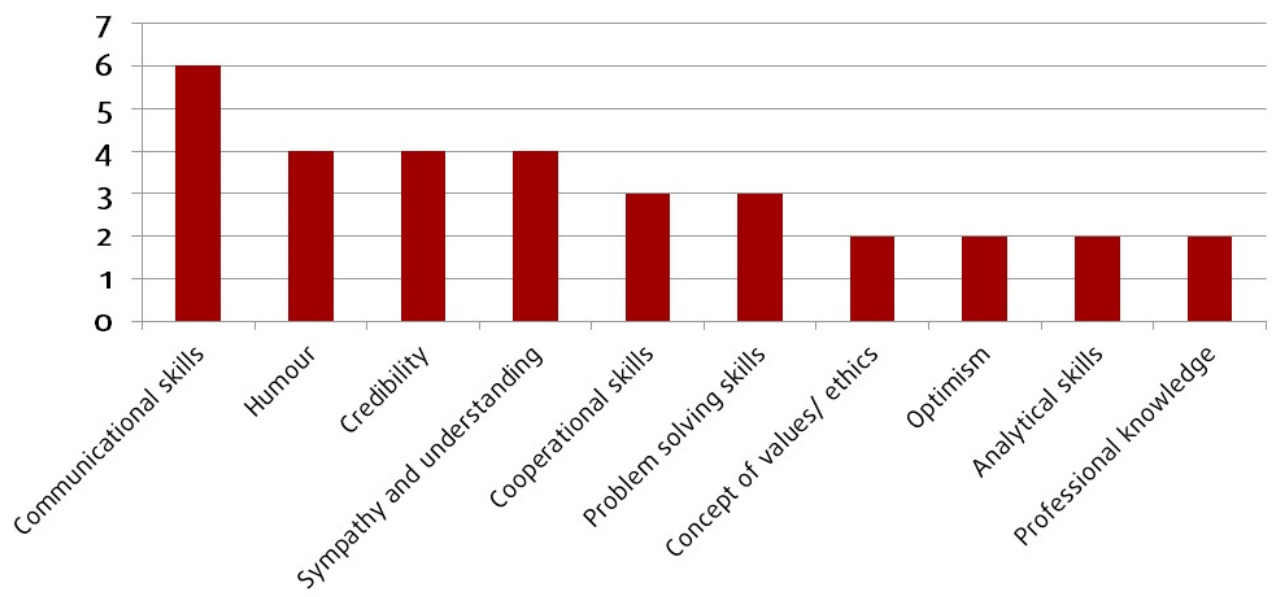

Figure 5. Results "Competence Cards - Communication" 
As can be seen in fig. 6, the mentioned competences are heterogeneous and therefore no clear conclusions can be drawn as of yet. The item "communication skills" with its six mentions is clearly the most frequent. The other competences can be divided into three clusters having four, three and two mentions respectively.

Using the card technique for leadership, the results for the preferred competences can be summarised as follows: optimism, credibility, decision-making ability, ability to work under pressure and judgment. Similar to the questioning concerning the competence communication, there are two front runners - in this case optimism and credibility. The other competences are mentioned, but three and eleven items respectively are mentioned equally often. A clear differentiation cannot be obtained using the current data.

Double mentions were observed in the data from the card technique for the competence of credibility, which is mentioned as the most frequent competence concerning "communication and leadership". In total, the authors detected a large number of double mentions: 14 competencies were allocated to both items of communication and leadership (see also Fig. 7).

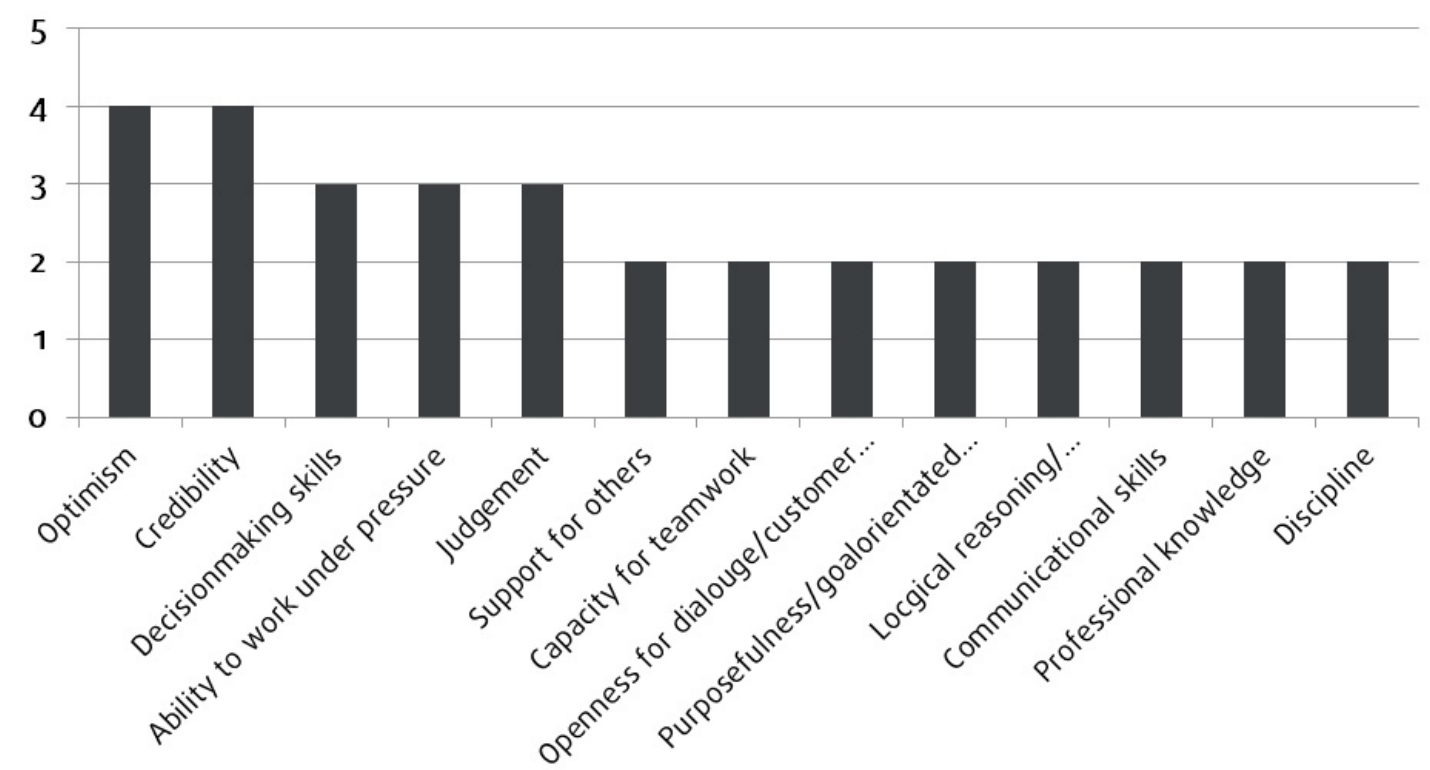

Figure 6. Results "Competence Cards - Leadership"

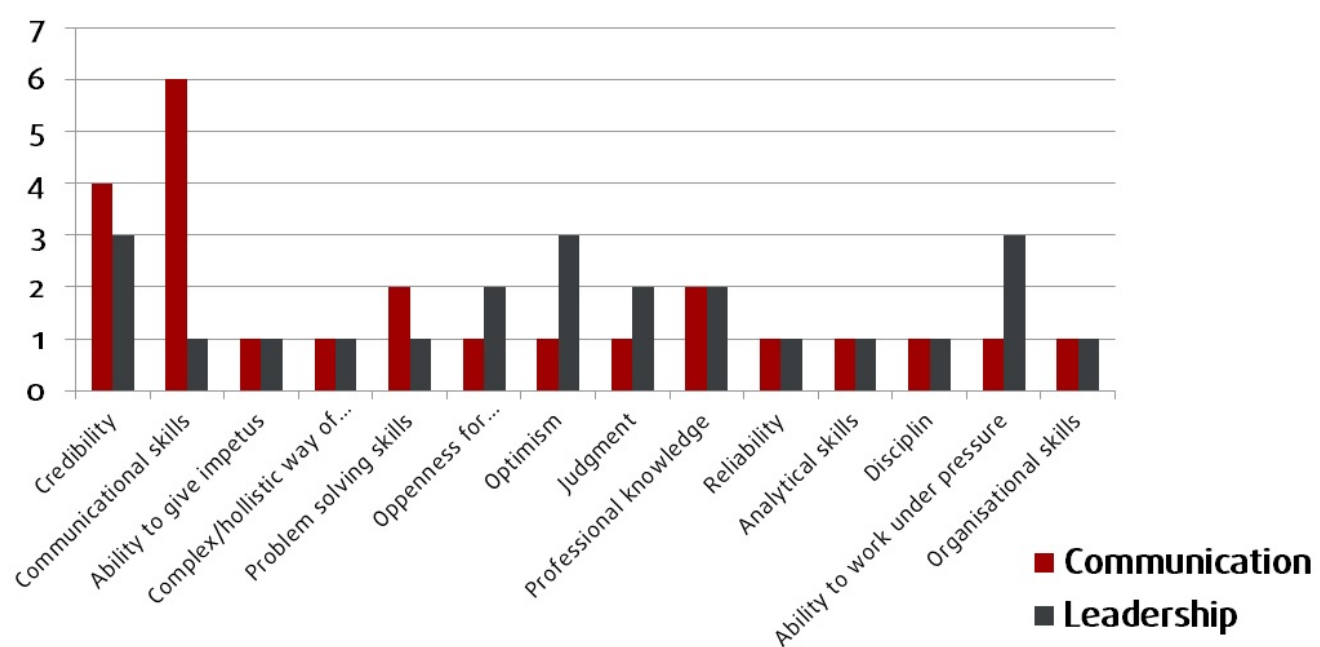

Figure 7. Competence cards allocated to both communication and leadership 
The occurrence of contradictions and double mentions need to be carefully considered. It seems that there is a correlation between communication and leadership when looking into competences. The allocated competences are of great significance to the outdoor instructors.

The significance of communication and leadership competences for the perceived success of outdoor instructors with their training groups can only be partly confirmed. The allocated competences from the open questions are perceived to be important, but are not spontaneously considered as communication and leadership competence. Through the card technique method, the allocated competences were considered to be important. The card technique does not show a consistent profile for the interviewed group.

\section{Discussion}

The job profile of an outdoor instructor is neither clearly defined, standardised nor officially recognised [8]. Consequently, the backgrounds and educational levels of outdoor instructors in Germany vary. For this reason the selection of suitable instructors for training providers can be challenging. The instructor is the most crucial factor for a successful outdoor training, as well as for the success with customers [14].

Since there is no clarity regarding requirements and competences of outdoor instructors even in current research, the goal of this pilot study was to create a basis for an outdoor instructor qualifications profile $[2,4,5,6,7$, 18]. The sample of this pilot study is small $(\mathrm{N}=10$ participants), but it has produced valuable initial results.

For the survey, instructors were consulted who can be considered experts in the field of outdoor training. The use of qualitative methods and procedures was positive, including the use of the Heyse and Erpenbeck [15] model. The participants did not miss any essential competences in the Heyse and Erpenbeck model and could understand all of the 64 competences. The results show that specific professional knowledge regarding outdoor sports or outdoor activities is indispensable for outdoor instructors. The interviewed group, however, ranked other competences of outdoor instructors (often referred to as "soft skills" by the interviewed persons) higher, since they are more difficult to learn or since a behaviour modification could not be carried out without considerable effort. This supports theories by Shooter, Sibthorp and Paisley [2]. From the perspective of the interviewed persons, successful outdoor instructors must possess a positive competence profile in the fields of personal competence, socio-communicative competence, activity competence and decision-making competence already at the start of their careers. This supports the definition by the GAIOE [19].

For all interview participants it is essential that the instructor is genuine, which means that he is able to set an example through his own actions and that he convincingly represents his affinity for outdoor activities. This supports previous research and models by Phipps and Swiederski [36] and Anderson and Absolon [4]. Furthermore he should be a positive person with a good sense of humour who can adapt successfully to individuals and groups, as Harvey [6] suggests according to his experience. The participants with long-standing work experience describe experience and a multitude of methods and behaviours in specific situations as their special personal strengths. Something Apitzsch [12] also finds for sports trainers. According to statements from the interviewees, it is an advantage to plan with foresight, to respond to situations flexibly and to make constructive decisions under pressure. At the same time the customer and his training goals should always be in the centre of attention. It can also be concluded, that an outdoor instructor must be proficient in his methods and he must be able to pass them on successfully. When asked about their own strength, interviewees talked about personal experiences. These experiences enable them to respond flexibly to individuals, groups and situations during training. This goes in line with Shooter, Sibthorp and Paisley [2] who underline the importance of experience and gut feeling. They also state that it is not really a soft or a hard skill, but something that influences the trainer strongly in what he does and why. Crucial points for the outdoor instructors were also authenticity as well as communication. The interviewees stressed the fact that they strive for authentic behaviour and clear communication. Within the framework of this pilot study the researchers could not prove if the competence of communication was mentioned by the interviewees since the focus of the question before was set on communication. The interviewed persons also stated their sensitivity towards people and their own empathy as their strengths. The mentioned strengths do not directly correlate to the competences that are considered important. It seems that they take their methodological skills and professional knowledge for granted and describe what makes them special apart from these.

Communication and leadership are seen as essential competences, but are not directly associated with specific competences and situations during trainings. Competences in the field of outdoor training cannot be allocated selectively by the interviewed outdoor instructors. Heyse and Erpenbeck [15] describe leadership as a cross-sectional competence. Some of the important aspects such as judgemental skills, organisational skills, credibility, communicational skills and conflict resolution are mentioned by the interviewees. Interestingly they are not especially mentioned when asked about leadership but throughout the whole interview. The similarity between sports coaching and outdoor training in relation to the leadership concept by Koenig [21] become evident.

A final interpretation is not yet possible on the basis of 
the data set. Based on the responses of the participants, it is inclusive which competences are particularly important in their view for successful outdoor instructors. The reason for this may be that many different competences are relevant [7]. Another reason could be that an instructor often assumes different roles during training sessions: according to the chronology of the training day he is sometimes more, sometimes less included in the group, helps with the cooking or guides a challenging team exercise [18]. Further research needs to explore whether it is sensible to make a division into hard and soft skills or even to add a third category of experience and decision-making as described by Shooter, Sibthorp and Paisley [2]. Further research, qualitative and quantitative, is necessary in order to be able to make general statements.

Looking at the results it can be said that there are parallels to the concept of effective coaching in team sports [40]. Therefore it might be valuable for future research to look into the strategies and methods of effective coaching [41] and to test their application in outdoor training. Although there are a lot of differences they both have a lot in common, especially regarding the importance of communication and leadership [42].

\section{Conclusions}

The pilot study presents initial findings that justify follow-up research, including quantitative research designs. Future research could attempt to reach a larger sample, of both genders or to have the authors continue to examine the interaction with the appreciated and felt competences by the participants.

It remains to be seen if a clear competence profile for outdoor instructors can be established. It is possible, however, to narrow down and define significant competences. The competence atlas by Heyse and Erpenbeck [15] seems appropriate for the field of outdoor instructors as the 4 categories they provide could be verified in this study. The research helps to specify a job profile of outdoor instructors in Germany. It can also be stated that communication and leadership competences are significant for the successful work of outdoor instructors and that these competences should be accordingly developed.

It can be said that an outdoor instructor needs a different variety of competences and it is hard to eliminate the ones most important. As one participant said: "At the end of the day an outdoor trainer is in my opinion an egg-laying wool-milk-pig (German saying about someone who can do everything), who can do everything somehow, is always in a good mood, and likes what he does" (Participant 2).

\section{REFERENCES}

[1] M. Ringer. Leadership Competences for Outdoor Adventure:
From Recreation to Therapy. In Adventure-Based Interventions with Young People in Trouble and at Risk. Proceedings of a National One-Day. Conference "Adventure-Based Interventions" (April 22, 1994), pp. 29-52, 1994.

[2] W. Shooter, J. Sibthorp, K. Paisley. Outdoor Leadership Skills: A Programme Perspective. Journal of Experiential Education, 32(1), pp.1-13, 2009.

[3] D. Sugermann. Outdoor Leadership Education: The Past, Present and Future. In ICORE'98: Proceedings from the International Conference on Outdoor Recreation and Education (12th, Fort Walton Beach, FL, October 20-24, 1998), pp.75-8, 1999.

[4] D. Anderson, M. Absolon. Expedition Planning, Stackpole Books, Mechanisburg, 2011.

[5] J. Graham. Outdoor Leadership: Technique, Common Sense, and Self Confidence, Mountaineers Books, Seattle, 1997.

[6] M. Harvey. The National Outdoor Leadership School's Wilderness Guide, Fireside, New York, 1999.

[7] S. Priest, M.A. Gass. Effective Leadership in Adventure Programming, Human Kinetics, Champaign, IL, 2005.

[8] K. Koenig, A. Koenig. Outdoor Teamtrainings: Von der Gruppe zum Hochleistungsteam. [Putdoor Teamtrainings: From a Group to a High Performance Team], Ziel, Augsburg, 2005.

[9] W. Michl. Erlebnispädagogik [Outdoor Education], Ziel Augsburg, 2007.

[10] J. Fengler. Erlebnispädagogik und Selbstkonzept: Eine Evaluationsstudie [Experiential Learning and self-concept. An evluative study], Logos, Berlin, 2007.

[11] N. Schad. Outdoor-Training - Regenwürmer oder Spanferkel? In: N. Schad \& W. Michl (Ed.). Outdoor-Training. Personal- und Organisationsentwicklung zwischen Flipchart und Bergseil (S. 89-104), Ernst Reinhardt Verlag, München, 2007.

[12] T. Apitzsch. Kompetenzprofile von Trainern und Sportmanagern im Leistungssport. [Competence profiles of coaches and sports managers in professional sports], Dissertation, Cologne, 2012.

[13] D. Gnahs. Kompetenzen - Erwerb, Erfassung, Instrumente [Competencs - Acquisition, Compilation and Instruments], wbv, Bielefeld, 2007.

[14] R. Buckley. Communications in Adventure Tour Products: Health and Safety in Rafting and Kayaking, Annals of Tourism Research, 2010. doi:10.1016/j.annals.2009.10.011.

[15] V. Heyse, J. Erpenbeck. Competence Training, Schaeffer-Poeschel, Stuttgart, 2009.

[16] L. von Rosenstil. Arbeits- und Organisationspsychologie: Management und Führung, [Industial- and Organisationalpsychology: Management and Leadership], In: G. Krampen (Ed.), Psychologie - Experten als Zeitzeugen [Psychology - Experts as Contemporary Witnesses], pp. 195-212, Hogrefe, Göttingen, 2009.

[17] S. Beck. (2005). Skill Management - Konzeption für die betriebliche Personalentwicklung, Deutscher 
Universitätsverlag, Wiesbaden, 2005.

[18] P. Rohwedder. Outdoor Leadership: Führungsfähigkeit, Risiko-, Notfall- und Krisenmanagement für Outdoorprogramme. [Outdoor Leadership: Leadership competence, Risk-, Emergency-, and Crisismanagemenet,] Ziel, Augsburg, 2008.

[19] GAIOE-German Association of Individual and Outdoor Education. Qualitätsgrundlagen für Anbieter erlebnispädagogischer Aus- und Weiterbildungen, die im Bundesverband Individual-und Erlebnispädagogik e.V. organisiert sind. [Education Standards for Providers of Experiential Learning Instruction that are organized within the German Association of Individual and Outdoor Education] internal document, Dortmund, 2015.

[20] M. Lames. Leistungsfähigkeit, Leistung und Erfolg - ein Beitrag zur Theorie der Sportspiele. Sportwissenschaft, 28, S. 137-152. 1998

[21] S. König. Führungsprinzipien von Sportspieltrainern. In K. Weber, D. Augustin, P. Maier \& K. Roth (Hrsg.), Wissenschaftlicher Transfer für die Praxis der Sportspiele (S. 72-76), Sportverlag Strauss, Köln, 2006.

[22] M. Muckenhaupt, L. Grehl, J. Lange. Der Trainer als Wissensexperte - Eine Studie zum Informationsverhalten, -bedarf und -angebot im Spitzensport, Hofmann, Schorndorf, 2009.

[23] J. Friebe. Merkmale unternehmensbezogener Lernkulturen und ihr Einfluss auf die Kompetenzen der Mitarbeiter [Aspects of company related cultured of learning and their influence on the competences of employees], dissertation, Heidelberg, 2005.

[24] N. Schaper, Schlömer, T., Paechter, M. Kompetenzen, Kompetenzorientierung und Employability in der Hochschule [Competencies, competenceorientation and emloyability in universities]. Zeitschrift für Hochschulentwicklung, 7, 2012.

[25] A. Diez. Entwicklung eines Konzeptes zur Personalentwicklung für eine technische Universität [Developing a human resources development concept for a technical university], dissertation, Dortmund, 2010.

[26] B.J. Avolio, B.M. Bass. Multifactor Leadership Questionnaire, Mind Garden Manual, Lincoln, 2004.

[27] U. Lakemann. Theoretische und empirische Grundlagen der Wirkungsimpulse von Erlebnispädagogik und Outdoor-Training. [Theoretical and Empirical Fundamental Effects of Experiential Learning and Outdoor-Training] In: U. Lakemann (Ed.): Wirkungsimpulse von Erlebnispädagogik und Outdoor-Training: Empirische Ergebnisse aus Fallstudien. [Effects of Experiential Learning and Outdoor-Training: Empirical Research and
Case-studies], Ziel, Augsburg, 2005.

[28] H. D. Lasswell. The Structure and Function of Communication in Society. In: Bryson, Lyman (Ed.) The Communication of Ideas. A Series of Addresses. New York, pp. 32-51. 1948 .

[29] C.E. Shannon, W. Weaver. The mathematical theory of communication, Urbana, Illinois, 1949.

[30] K. Buehler. Sprachtheorie [Theory of Language], UTB, Stuttgart, 1968.

[31] N. Chomsky. Syntactic Structures, Mouton, The Hague, 1957.

[32] P. Watzlawick, J.B. Bavelas, D.D. Jackson. Menschliche Kommunikation. Formen, Störungen,

Paradoxien.[Pragmatics of Human Communication], Huber, Bern, 1969.

[33] F. Schulz von Thun. Miteinander reden 1-3. Allgemeine Psychologie der Kommunikation. [Talking with each other 1-3. General Psychology of Communication], Rowohlt, Reinbek, 1981.

[34] L.H. Buell. Outdoor leadership competency: A manual for self-assessment and staff evaluation, Environmental Awareness Publishers, Greenfield, MA, 1983.

[35] D.H. Johnson, F.P. Johnson. Joining Together: Group Theory and Group Skills, Pearson, Harlow, 1987.

[36] M. Phipps, M.Swiderski. The soft skills of outdoor leadership. In J.C. Miles \& S. Priest (Ed.). Adventure Education (S. 113-118) Venture, State College, PA, 1990.

[37] J.Glaeser, G. Laudel. Experteninterviews [Interviewing Experts], Springer, Wiesbaden, 2010.

[38] P. Mayring. Qualitative content analysis. In U. Flick von E. Kardoff., I. Steinke. (Ed.). A companion to qualitative research, pp. 266-269, 2004.

[39] K. Lewin, Lippitt, R., White, R.K. Patterns of aggressive behavior in experimentally created social climates, Journal of Social Psychology, 10, pp.271-301, 1939.

[40] G. Wade. An integrative definition of coaching effectiveness and expertise, International Journal of Sports Science \& Coaching, 4 (3). pp. 307-323, 2009

[41] A. Bennie, O'Connor, D. An Effective Coaching Model: The Perceptions and Strategies of Professional Team Sport Coaches and Players in Australia, International Journal of Sport and Health Science, 9, pp 98-104, 2011.

[42] A. Laios, Gargalinos, D. Leadership and power: two important factors for effective coaching, International Sports Journal, pp. $150-154,2003$. 